\title{
Ten years water and energy surface balance from the CNR-ISAC micrometeorological station in Salento peninsula (southern Italy)
}

\author{
P. Martano ${ }^{1}$, C. Elefante ${ }^{2}$, and F. Grasso ${ }^{1}$ \\ ${ }^{1}$ CNR-Istituto di Scienze dell'Atmosfera e del Clima - UOS Lecce, Via Monteroni, 73100 Lecce, Italy \\ ${ }^{2}$ Ripartizione Informatica, Università del Salento, Viale Gallipoli 49, 73100 Lecce, Italy \\ Correspondence to: P. Martano (p.martano@ isac.cnr.it)
}

Received: 14 January 2015 - Revised: 27 May 2015 - Accepted: 1 June 2015 - Published: 16 June 2015

\begin{abstract}
Data of surface-atmosphere energy and water transfer from a ten years (2003-2013) period of activity of the ISAC-Lecce micrometeorological station (http://www.basesperimentale.le.isac.cnr.it) have been analyzed: to the authors' knowledge this is the first decadal data set of surface-atmosphere transfer in Salento peninsula. The surface energy budget shows a tendency to a positive bias possibly due to several reasons that require more investigations. Some suitable indices related to the surface water balance, such as the precipitation intensity, the aridity index and the ground water infiltration fraction have been calculated. Possible trends of these annual averages in the decadal period are considered, also taking into account the statistical uncertainty associated to measurement errors and missing data. The results indicate a significant increasing in the precipitation intensity together with an experimental evidence of increasing of the ground water infiltration in the measurement area, that is in agreement with recent estimations for the whole Salento peninsula. On the other hand, recent studies show that seawater intrusion and salinization of the deep underground aquifer keep increasing in the same period.
\end{abstract}

\section{Introduction}

Semi-arid coastal regions are common in Mediterranean areas. The correct assessment of the surface water and energy balance can be difficult for such regions, due the extreme changes in the surface moisture conditions that require direct measurements. Indeed reliable estimates of evapotranspiration generally based on the potential evaporation concept (Allen et al., 1998) are not easy to obtain over surfaces that are often in very dry conditions. In this context evapotranspiration constitutes one of the less known components of the surface water budget especially for climatic studies, and long term time series of measurements are often not easy to be found. Long term measurements of the surface water balance can be also helpful for the management of the often scarce fresh water resources. Indeed coastal groundwater aquifers are often the only fresh water supply for the local populations, and imbalance between drainage and recharge by surface infiltration can lead to loss of pressure and seawater intrusion in the aquifer, significantly degrading water quality (Custodio, 2010; Delle Rose et al., 2000). Salento peninsula, in the south-east of the Italian peninsula (Fig. 1) is a semiarid region characterized by an almost plane surface with a small orographic relief in the south-west part $(200 \mathrm{~m}$ height). The non-urbanized lands are generally covered by olive groves, vineyards or arable lands, mostly non-irrigated, while few remaining natural extensions are characterized by pine forests or mixed Mediterranean shrubs. The precipitation climatology is typically Mediterranean with warm dry summers and quite mild wet winters. The average annual precipitation is about $650 \mathrm{~mm}$ but with a certain variation within tens of kilometres due to the particular geographical shape of the southern end. This, together with the presence of the low orographical relief, triggers air lifting and a convergence zone, thus enhancing local precipitation in this area (Fig. 1). The average annual temperature is about $16-17^{\circ} \mathrm{C}$, with a spatial variation of about $1{ }^{\circ} \mathrm{C}$ from the east to the west coast that is not directly exposed to the mistral winds. Indeed the wind regime has two main components: southwest, prevailing in cyclonic conditions, and north-west, that 


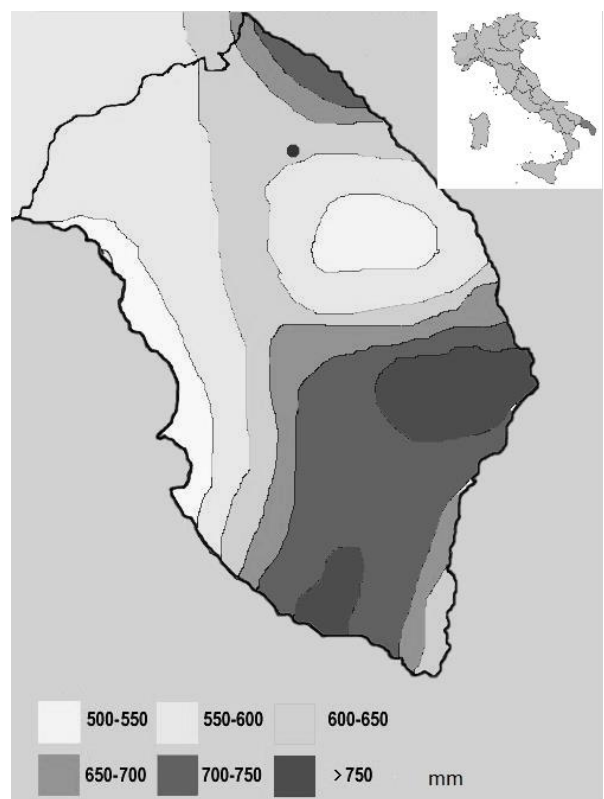

Figure 1. Salento peninsula with averaged 1921-1996 precipitation distribution (mm) (adapted from http://www.supermeteo.it). The dot indicates the measurements site.

are quite common in this area due to the channelling effect of the Otranto channel, and are prevailing in anti-cyclonic conditions. Hydrology is characterized by ephemeral stream systems and karstic geological characteristics that allow the presence of a deep good quality ground water aquifer, the major source of freshwater for anthropic use (more than $80 \%$ of the total fresh water necessity in the area). Monitoring and modelling studies of the aquifer balance in the last decades (Margiotta and Negri, 2005; Portoghese et al., 2005; Romanazzi and Polemio, 2013) showed a decreasing aquifer pressure with increasing salty seawater intrusion. Thus, efforts have been recently made to specifically modelling the groundwater flow in the fractured karst aquifer (Giudici et al., 2012; De Filippis et al., 2013). The aim of this work is to present a data set of long term experimental measurements of the surface energy and water balance as measured by the CNR-ISAC micrometeorological station in Salento peninsula (the only available long term data set in Salento, to the authors' knowledge), and to give an experimental support to the hydrological modelling for the local water resources management.

\section{Data processing}

\subsection{Data collection}

The CNR-ISAC micrometeorological base is placed in a suburban area $5 \mathrm{~km}$ south-west from Lecce (Fig. 1), within the Salento University campus (Lat: $40^{\circ} 20^{\prime} 12^{\prime \prime}$ Lon: $18^{\circ} 7^{\prime} 17^{\prime \prime}$ ) characterized by mixed typical local vegetation (pines, olive groves and Mediterranean shrubs) with an increasing content of buildings and non-natural surfaces. Buildings and trees have an average height of about $10 \mathrm{~m}$ and with estimated roughness length $z_{0}$ and displacement height $\mathrm{d}$ of about 0.5 and $7 \mathrm{~m}$ respectively (Martano, 2000). A $16 \mathrm{~m}$ high mast is equipped with a fast response eddy covariance system and standard meteorological sensors for routinely collecting half-hour averaged data of air temperature and humidity. The mast height allows a flux footprint fetch of the order of several hundreds of meters (Hsieh et al., 2000), thus taking contributions from the campus and some immediately surrounding vegetated areas. An ancillary Campbell meteorological station collects measurements of air temperature, air humidity and net radiation and soil surface measurements of temperature, soil moisture and soil heat flux. Data are averaged and stored either in a data logger (meteorological station) or in a dedicated netbook for fast response data processing (eddy covariance system), that outputs halfhour averaged turbulent flux data in the streamline coordinate system (McMillen, 1988). Before the final storage in the web database as $30 \mathrm{~min}$ averages, data undergo a quality control that eliminates out of range measurements generated by possible malfunctioning of the sensors. A site map and a more detailed description of the station are available elsewhere (http://www.basesperimentale.le.isac.cnr.it, Martano et al. 2013).

\subsection{Time series post processing}

The $30 \mathrm{~min}$ averaged data time series have been post processed trying to minimize the possible uncertainties and errors coming from the measurement procedure, such as the eddy covariance method for the turbulent fluxes of heat and water vapor (Foken and Wichura, 1996). Massman (2000) spectral corrections and mass flux Webb corrections (Webb et al., 1980) have been applied. In addition an estimation of the uncertainty to be associated to the annual cumulative and/or average value has been attempted. It has been defined as the maximum between the uncertainty associated to the measurement procedure (instrumental uncertainty for slow response measurements and statistical uncertainty for eddy covariance measurements), and the uncertainty associated to gaps of data lacking in the time series (however, annual time series with more than 1 month total data gap have not been used). The statistical uncertainty $E_{\text {ec }}$ associated to the eddy covariance fluxes $<w^{\prime} q^{\prime}>$ was estimated as the standard deviation of the instantaneous measurements $w^{\prime} q^{\prime}$ in the averaging time (30 $\mathrm{min})$.

An evaluation of the uncertainties associated to the presence of gaps of $\mathrm{d} N$ data in the (annual) time series of $N$ (30 min averaged) measurements is proposed as (if $\mathrm{d} N \ll N)$ :

$E_{\text {ave }}=\sigma_{N}(\mathrm{~d} N / N)^{1 / 2}$ for average values and $E_{\text {cum }}=Q \mathrm{~d} N / N$ for cumulant values (total sum) where 


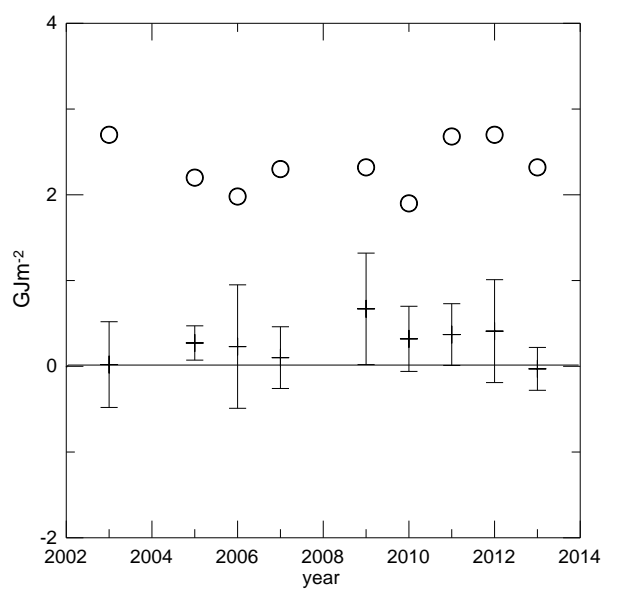

Figure 2. Total annual surface energy balance $\left(R_{\mathrm{n}}-G-\mathrm{LE}-H\right)$ compared with the measured annual net radiation ( $R_{\mathrm{n}}$, circles $)$.

$\sigma_{N}$ is the standard deviation of the (annual) time series and $Q$ its sum.

Besides directly measured quantities some other derived indices are used in the following analysis:

- Evaporative Fraction $\mathrm{EVF}=\mathrm{LE} /(\mathrm{LE}+H)$ where $\mathrm{LE}$ and $H$ are respectively the latent and sensible heat fluxes.

- Aridity Index $\mathrm{AI}=P / \mathrm{ET}_{0}$ where $P$ and $\mathrm{ET}_{0}$ are the precipitation and the potential evapotranspiration calculated by the Penman-Monteith formula (Allen et al., 1998).

- Water Infiltration Fraction $\mathrm{WIF}=(P-\mathrm{Ev}) / P$ where $\mathrm{Ev}$ is the actual (measured) evapotranspiration and runoff is neglected, that is a very reasonable assumption in the measurement area, and quite generally also in Salento peninsula (Portoghese et al., 2005).

- Precipitation Intensity PI $=\langle P\rangle_{\text {wd }}$ where $\langle\ldots\rangle_{\text {wd }}$ indicates the time series average for wet days only (days in which $P>1 \mathrm{~mm}$ ).

In addition the North Atlantic Oscillation Index NAO (difference between the measured sea level atmospheric pressure in Lisbon and Reykjavik) has been computed for the same periods by web data (http://www.cpc.ncep.noaa.gov/products/ precip/CWlink/pna/nao.shtml).

\section{Results and discussion}

The annual averages of the energy balance $\left(R_{\mathrm{n}}-G-\mathrm{LE}-H\right.$, where $R_{\mathrm{n}}$ is the net radiation and $G$ the soil heat flux at $2 \mathrm{~cm}$ depth) are shown in Fig. 2. Although the budget appears to be generally closed within the quite large uncertainties, a tendency to a positive imbalance is also apparent. Several reasons can contribute: from the

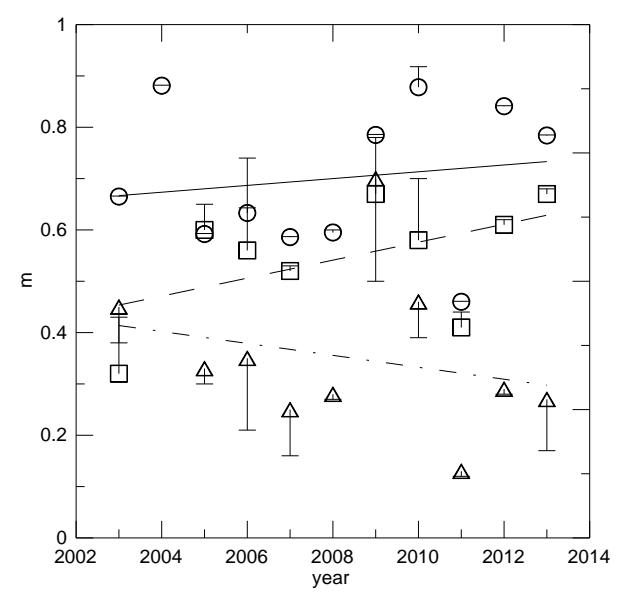

Figure 3. Annual averages of precipitation (m, circles), water infiltration fraction (squares) and aridity index (triangles) with estimated maximum uncertainties. The continuous $(P)$ dashed (WIF) and dash-dotted (AI) lines are least squares linear regressions.

divergence of the soil heat flux between the surface and $2 \mathrm{~cm}$ depth, to the tendency of the eddy correlation system to underestimate the turbulent fluxes due to the finite averaging time (Cava et al., 2008). Even possible uncertainties in the calibration of the net radiometer after suffering strong rain events with dome breaking cannot be excluded, and all will require a separate analysis. Figure 3 shows some trends for the water balance: total precipitation, water infiltration fraction and aridity index. Here and in the next figure two tests have been performed to check the decadal trends. In the first the sign of the trend has been checked after deleting the first and the last annual average in the series, while in the second the statistical uncertainty of the regression slope was calculated to verify whether a change of sign of the slope were possible within the slope uncertainty. The trend is considered significant if both tests give negative result (no change in the slope sign), marginally significant if only one of them gives negative result, and not significant if both give positive result. In Fig. 3 the trends are marginally significant and positive for both total precipitation and water infiltration fraction, while the $\mathrm{AI}$ is decreasing, indicating a probable decrease in the year-averaged surface soil moisture, as $\mathrm{AI}$ is quite well correlated with local soil moisture measurements when available (correlation coefficient 0.85 for annual averages). The apparent disagreement between these last results (increasing precipitation and infiltration, and decreasing surface soil moisture) is perhaps less surprising when observing Fig. 4, that shows a significant positive trend for the total precipitation intensity. It is possible that the increasing concentration of precipitation events in an otherwise semi-arid region with karstic geologic features and generally negligible slopes and runoff is likely to increase infiltration more than evaporation. This is because the soil surface becomes wet within short time intervals 
during the year, while it is going to dry up quickly in a few days after rain, preventing strong long term evaporation. The NAO negative trend also shown in Fig. 4 suggests that the locally measured increasing precipitation intensity could be linked to a regional trend of increasing precipitation associated to the decreasing NAO phase during the decade of observations (Willems, 2013). A recent statistical downscaling analysis also found a scenario of increasing precipitation intensity, over this region for the next decades, especially in the dry season (Palatella et al., 2010). These results suggest a potentially increasing availability of water recharge for the groundwater aquifers during the past decade in the measurement area. Although the extension of this experimental result to the whole Salento peninsula would require more measurement sites, this possibility is suggested by the following remarks. Indeed the measurement site is far from the maximum of the precipitation distribution (Fig. 1) and characterized by Mediterranean arboreus vegetation that tends to enhance and stabilize evapotranspiration with respect to bare soil or dry shrub Mediterranean areas (Scanlon et al., 2006). Thus the annual difference between measured precipitation and evapotranspiration is not expected to overestimate the average over the Salento peninsula and the measured positive trend of the surface infiltration also appears as an experimental confirmation of recent estimations for the whole peninsula (Portoghese et al., 2013). This trend can be constrasted with a recent analysis of the available data from monitoring wells by Fidelibus and Tulipano (2014), showing that the freshwater column thickness of the local deep aquifer keeps decreasing during the last decade, together with an increasing height of the freshwater-seawater interface under Salento peninsula. In synthesis, the water surface budget measurements presented here give an experimental evidence of an increasing availability of potential groundwater recharge by infiltration, still not affecting the increasing salinization and marine intrusion in the Salento deep aquifer in the last decade.

Acknowledgements. The authors wish to acknowledge the PON 2007-13 I-AMICA (OR1) project (http://www.i-amica.it), and the CNR GIIDA project (http://www.dta.cnr.it/content/ view/2735/244/lang,en/), for partially supporting the micrometeorological base and the database, and the HyMeX project (http://www.hymex.org) for the scientific support.

Edited by: F. C. Bosveld

Reviewed by: S. Margiotta and another anonymous referee

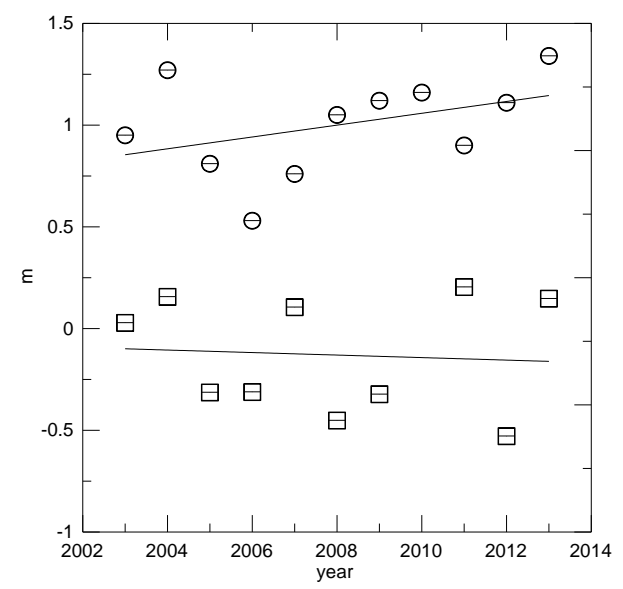

Figure 4. Annual averages of precipitation intensity (m, circles) and NAO (squares). The straight lines are least squares regressions.

\section{References}

Allen, R. G., Pereira, L. S., Raes, D., and Smith, M.: Crops Evapotranspiration: Guidelines for computing crop Water Requirements, FAO Irrigation and Drainage Paper 56, FAO, Rome, Italy, 300 pp., 1998.

Cava, D.,Contini, D., Donateo, A., and Martano, P.: Analysis of short-term closure of the surface energy balance above short vegetation, Agr. Forest Meteorol., 148, 82-93, 2008.

Custodio, E.: Coastal aquifers of Europe: an overview, Hydrogeol. J., 18, 269-280, 2010.

De Filippis, G., Giudici, M., Margiotta, S., Mazzone, F., Negri, S., and Vassena, C.: Numerical modelling of the groundwater flow in the fractured and karst aquifer of the Salento peninsula (Southern Italy), Acque Sotterrranee, 1, 17-28, 2013.

Delle Rose M., Federico A., Fidelibus C.. A computer simulation of groundwater salinization risk in Salento peninsula (Italy), in: Risk Analysis II, edited by: Brebbia, C. A., Wessex Institute of Tecnology, Southampton, 465-475, 2000.

Fidelibus, M. D. and Tulipano, L.: Monitoring seawater intrusion by means of long-term series of EC and T logs (Salento coastal karstic aquifer, Southern Italy), SWIM 23rd SaltWater Intrusion Meeting, 16-20 June 2014, Husum, Germany, 2014.

Foken, T. and Wichura, B.: Tools for quality assessment of surfacebased flux measurements, Agr. Forest Meteorol., 78, 83-105, 1996.

Giudici, M., Margiotta, S., Mazzone, F., Negri, S., and Vassena, C.: Modelling hydrostratigraphy and groundwater flow of a fractured and karst aquifer in a Mediterranean basin (Salento peninsula, southeastern Italy), Environ. Earth Sci., 67, 1891-1907, 2012.

Hsieh, C. I., Katul, G., and Chi, T.: An approximate analytical model for footprint estimation of scalar fluxes in thermally stratified atmospheric flows, Adv. Water Resour., 23, 765-772, 2000.

Margiotta, S. and Negri, S.: Geophysical and stratigraphical research into deep groundwater and intruding seawater in the mediterranean area (the Salento Peninsula, Italy), Nat. Hazards Earth Syst. Sci., 5, 127-136, doi:10.5194/nhess-5-127-2005, 2005. 
Martano, P.: Estimation of Surface Roughness Length and Displacement Height from Single-Level Sonic Anemometer Data, J. Appl. Meteorol., 39, 708-715, 2000.

Martano, P., Elefante, C., and Grasso, F.: A database for long term atmosphere-surface transfer monitoring in Salento Peninsula (Southern Italy), Dataset Papers Geosci., 2013, 946431, doi:10.7167/2013/946431, 2013.

Massman, W. J.: A simple method for estimating frequency response corrections for eddy covariance systems, Agr. Forest Meteorol., 104, 185-198, 2000.

McMillen, R.: An eddy correlation technique with extended applicability to non-simple terrain, Bound.-Lay. Meteorol., 43, 231245, 1988

Palatella, L., Miglietta, M. M., Paradisi, P., and Lionello, P.: Climate change assessment for Mediterranean agricultural areas by statistical downscaling, Nat. Hazards Earth Syst. Sci., 10, 1647-1661, doi:10.5194/nhess-10-1647-2010, 2010.

Portoghese, I., Uricchio, V., and Vurro, M.: A GIS tool for hydrogeological water balance evaluation on a regional scale in semi-arid environments, Comput. Geosci., 31, 15-27, 2005.
Portoghese, I., Bruno, E., Dumas, P., Guyennon, N., Hallegatte, S., Hourcade, J. C., Nassopoulos, H., Pisacane, G., Struglia, M. V., and Vurro, M.: Impacts of Climate Change on Freshwater Bodies: Quantitative Aspects, in: Regional Assessment of Climate Change in the Mediterranean, Advances in Global Change Research 50, Ch. 9, edited by: Navarra, A. and Tubiana, L., Springer, Dordrecht, 2013.

Romanazzi, A. and Polemio, M.: Modelling of coastal karst aquifers for management support: a case study of Salento (Apulia, Italy), Ital. J. Eng. Geol. Environ., 1, 65-83, 2013.

Scanlon, B. R., Keese, K. E., Flint, A. L., Flint, L. E., Gaye, C. B., Edmunds, W. M., and Simmers, I.: Global synthesis of groundwater recharge in semiarid and arid regions, Hydrol. Process., 20, 3335-3370, 2006.

Webb, E. K., Pearman, G. I., and Leuning, R.: Correction of flux measurements for density effects due to heat and water vapour transfer, Q. J. Roy. Meteorol. Soc., 106, 85-100, 1980.

Willems, P.: Adjustment of extreme rainfall statistics accounting for multidecadal climate oscillations, J. Hydrol., 490, 126-133, 2013. 